\title{
DIGITAL TWIN MODELS FOR MAINTENANCE OF CABLE-SUPPORTED BRIDGES
}

\author{
CS Shim*, HR Kang and NS Dang \\ Department of Civil Engineering, Chung-Ang University, Seoul, Korea \\ *Corresponding author
}

\begin{abstract}
Recently, long-span bridges have more than 100 years of service life. Since cable-supported bridges are key links in transportation networks, it is essential to manage the structures in a good service state. Most cable-supported bridges have bridge maintenance systems with monitoring sensors. However, records of damage and their repairs are not well managed. In this paper, a new bridge maintenance system was designed using a digital twin model concept. According to different maintenance tasks, inventory and information requirements were investigated. The digital model is a platform to collect, curate and share the maintenance history. For certain events, the model can be utilized for the analysis to consider any change of structural parameters. Recorded responses from sensors are used to update the digital twin model. Based on the design of the maintenance system, a pilot application on an existing cable-stayed bridge was conducted for a year and feedback was discussed. Extension of the application for a suspension bridge was also presented to generalize the methodology.
\end{abstract}

\section{Introduction}

Cable-supported bridges are one of the most important investments within the field of national transportation links and hold a service life exceeding 100 years. As the recent collapse of Morandi bridge indicates, the loss of transportation links brings serious social problems. Although the main cables of a suspension bridge which regards safety aspects do undergo tension force measurement, visual inspection is recommended to be conducted 30 years later (Mayrbaurl and Camo, 2004). Recently methodology of the evaluation of remaining service life of bridge cables was presented by Mahmoud (2011). In order to learn from similar cases and to prevent such incidents, new approaches for information exchanges are required. Considering how such various information, stockpiling from the very first step of designing bridges, will be used for the next 100 years by countless people, the limit of current information management and accumulation system maintained by a few experts is obvious.

Cable-supported bridges are normally equipped with a proper maintenance system and have a monitoring system running as well. Data on bridges accumulated during the operation period plays a significant role in evaluating load carrying capacity of the overall bridge system and managing fracture critical members. In the report of NCHRP 543, five types of microenvironments observed in bridge cables cause cable wire to crack and break, and sources of water penetration are presented. These lessons can be utilized for better bridge maintenance. Fractures caused by cable fire at the Seohae Grand Bridge in Korea showed the necessity for analytic evaluation of this bridge as well as for availability of data prepared any time to aid proper judgement of experts in order to immediately react to such incidents. Information that is not federated or un-digitalized cannot support resilient bridge management.

Ever since the application of Building Information Modelling (hereafter BIM) technology in the bridge technology field, innovative cases of designs as well as constructions have been presented (Lee et al., 2010; Shim et al., 2011, 2012, 2016). Once the life-span data management becomes possible, it can guarantee certainty to the designer about bridge behaviour and enhancement of design triggered by this certainty directly leads to overall cost saving. Cable-supported bridges, which has the longest design life, has to consider various factors such as aesthetic consideration, safety, constructability from the steps of designing, and resilience under unexpected situations is a newly added task to be considered. As small numbers of experts alone are dealing with design and construction, there are limits to understanding and responding to all the potential problems during the life span.

Maintenance and management system on structures based on BIM has been suggested by several experts (Shim et al., 2010, 2017). Three dimensional digital models play a role as a platform that allows input and output of relevant data. Attempts to develop data engineering-based interface system that monitors and records massive amount of data, produced during the process of design, construction, operation and maintenance, based on the model are being conducted beyond the scope of an individual structure. BIM based bridge maintenance system of the cable-stayed bridge, which was developed by Shim et al., (2017), is currently under test operation.

The concept of newly presented digital twin model (hereafter DTM) allows monitoring of multiple objects' behaviours like mechanical products and enables prediction of future 
performance during the operation period. DTM is a usefu approach even with cable-supported bridges that requires longterm constant management like health care of human body. Data of bridges behaviour in response to various occurring events collected by the monitoring system and going through interpretation linked to digital model can enable the analysis model with system update. This paper regards how the concept of digital twin model can be utilized for maintenance management with regard to cable-supported bridges.

\section{Digitalization of bridge information}

\subsection{Inventory and code system}

Currently, the information of the bridges is commonly managed by several reports. Accumulation, curation and use of the data of the bridge need to be efficiently managed according to digitalized model-based procedures. Suspension bridges and cable-stayed bridges have typical main members such as cables, pylons, stiffening girders, anchorages and foundations. Modelbased database system is linked with relevant 3D digital models.

Figure 1 Digital bridge models with relevant database
Digital models with whole data link provide innovative way of maintenance practices such as mobile, augmented reality devices, UAV scanning and automatic damage detection through artificial intelligence technology. For these purposes, the authored digital models need to be modified for maintenance system at the time of project delivery. Lighter models for mobile devices is better for various tasks. A bridge owner needs to decide the use of the models considering the main functions of the maintenance system.

\subsection{Damage definition}

According to SHRP 2 report (Atorod et al., 2013), bridges that have lasted more than 100 years have proven to have three aspects. The bridges were well maintained over their 100 -year live due to extreme importance or high replacement cost. The second reason is adaptability to change their functional use as well as service limit state demands. In early stage of the bridge design, those bridges were originally overdesigned. In order to have lessons from these records, it is necessary to define damage-related information for the DTM such as source of deterioration, deterioration mechanism, deterioration models and failure modes.

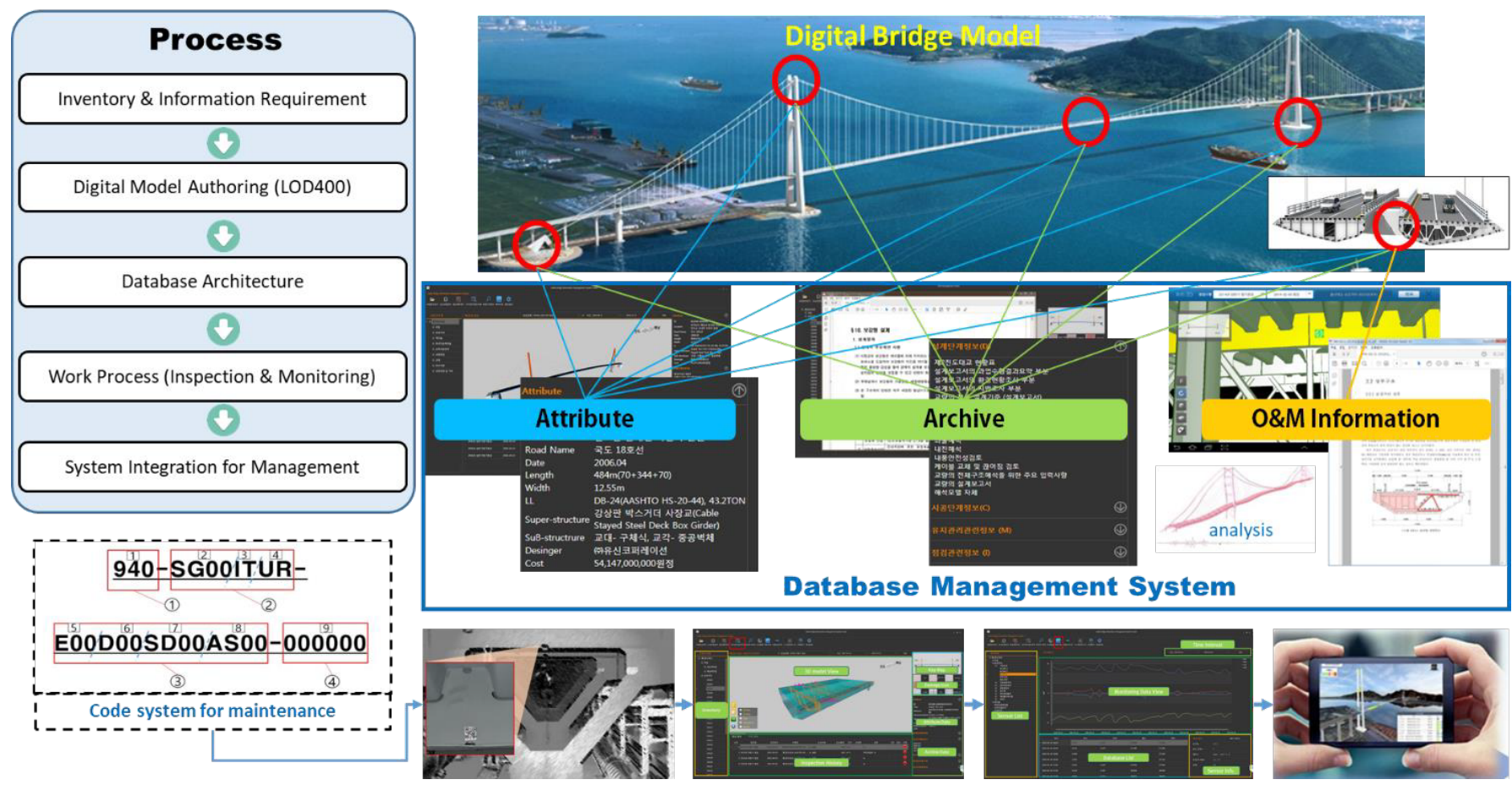

As shown in Figure 1, organization of bridge member inventory and its relevant information is defined. Digital models are authored according to the requirement of inspection practices. Database consists of attributes of each member and archive of submitted documents. During operation of the bridge, additional information is accumulated in the database. The model and the database is linked by the defined code system. The code definition should be established in national level so that network-level data curation can be performed to enable future performance prediction.
Deterioration models provide quantitative prediction of service life of bridge members, components, and subsystems. However, those models are very limited and mostly based on laboratory experience. Mathematical models and empirical models should be modified or calibrated using the data accumulated during long operation period of cable-supported bridges. Digital twin models and their data linked to the members provide data lake of the performance under certain conditions. The data lake is the concept of open data platform by the government considering data security. Deficiency fault 
trees (Atorod et al., 2013) can be defined to help the plan of information requirements.

Since the bridge owner established the guideline of bridge inspection practices, huge amount of inspected data have been accumulating. However, those data are not available for researchers who want to develop a deterioration model based on field performance. In order to overcome current situation, damage code system was proposed as shown in Figure 2 (Shim et al., 2019; Dang and Shim, 2018).

Damage recognition needs experience of experts who understand different causes under conditions of the bridge, as presented in Figure 3. However, most bridge owners and consulting companies lack of those experienced engineers. Thorough digitalizing of the inspection data, structures with certain damages has condition data which are linked to the bridge ID. Researchers can establish machine learning database for automatic damage inspection.

\subsection{Information requirements and delivery for maintenance}

Information requirements on the cable-supported bridge should be defined considering key issues of long-term and critical phenomena. The requirements are obtained from engineers and information manager of the bridge. Figure 4 describes an example of information delivery plan for a bridge. Current bridge maintenance practices follow a specific guideline which is established at the time of project handover. Most cable-supported bridges have long service time and documents which are not well digitalized for the system. However, the history of the inspection and assessment is crucial for the new maintenance system. According to the suggested information architecture, the information should be curated in order to be included in the digital models.

Decision making during the operation of the bridges depends on the accumulated information. Damage history is not enough to assess all aspects of function requirements such as safety, serviceability, durability and resilience. Through the interoperability of the digital model with numerical analysis models, the model needs to be updated in every periodical assessment process. Sensor data from the monitoring system is mostly available for the update.
Figure 2 Damage definition of concrete structures

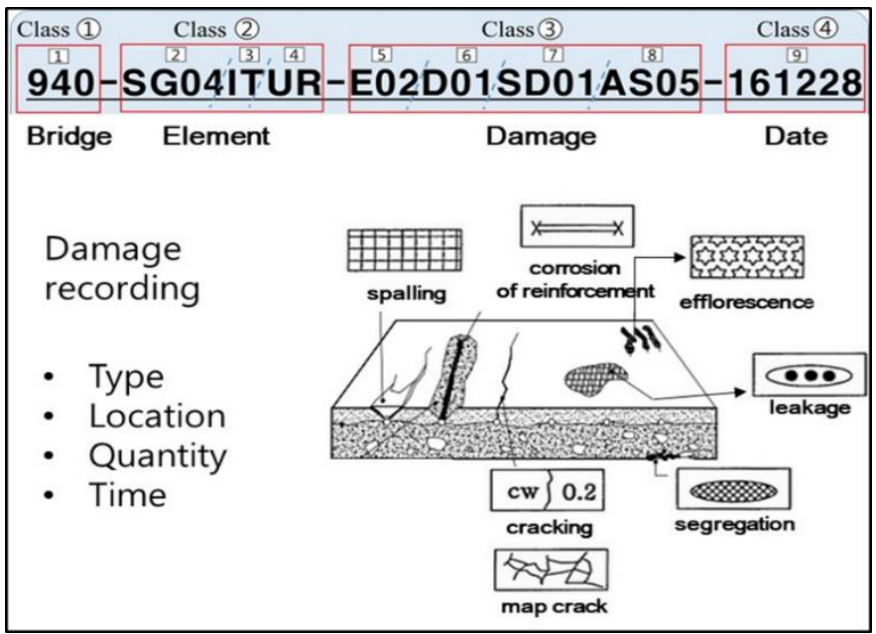

Figure 3 Causes by deficiency (Atorod et al., 2013)

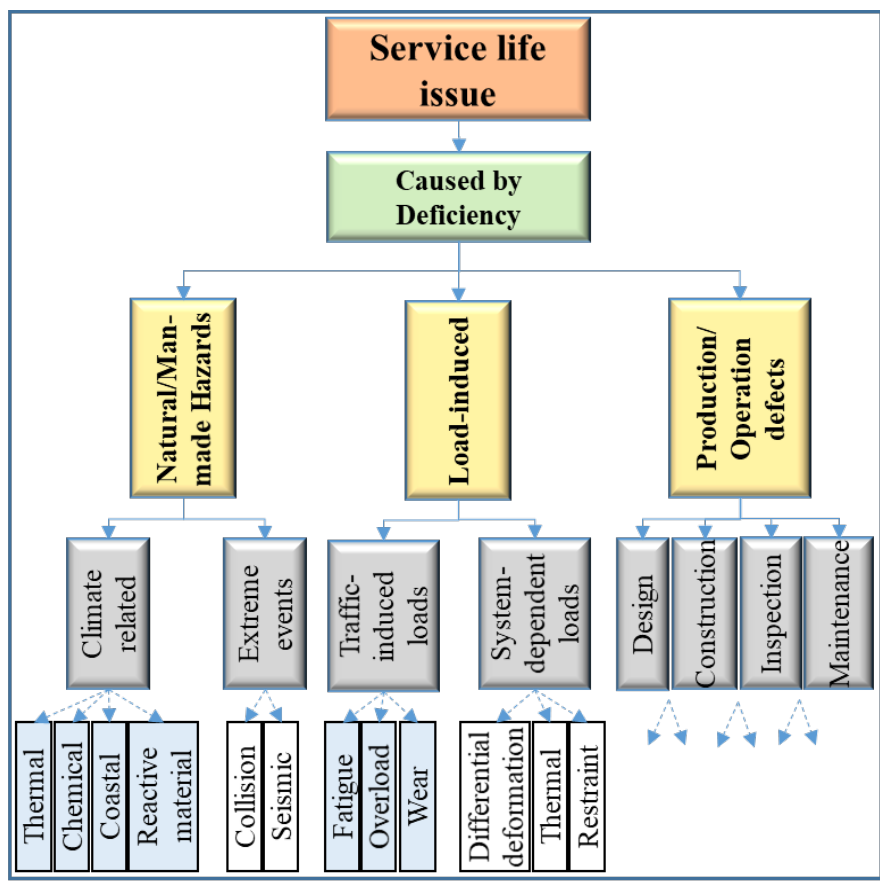

Figure 4 Information delivery plan

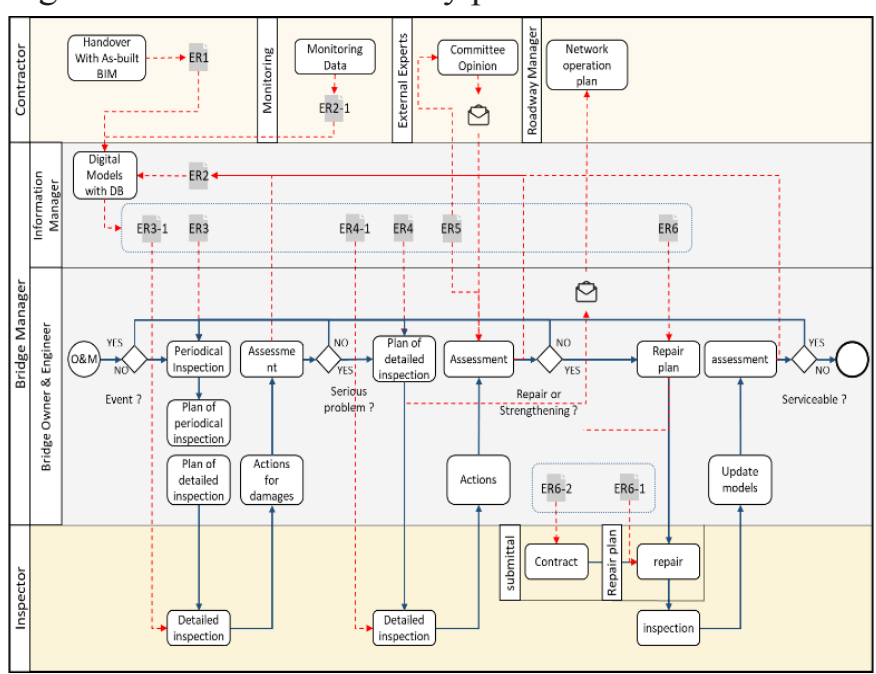




\section{Digital twin models for cable-supported bridges}

\subsection{Definition of digital twin models}

Definition of a digital twin model of a member in a cablesupported bridge should be different according to model uses. Figure 5 shows an example of a model of a stiffening girder in a suspension bridge. During the authoring stage of the model, rules in relevant design codes and specifications should be considered as constraints. Parametric modelling technique allows rule-based modelling for member dimensions, connections, and tolerance. Smart models provide engineers alternative sections or details for more efficient design process.

LOD (level of detail or development) or LOI (level of information) of the model for different uses needs to be considered in the federated model. A full bridge model utilize alignment of the bridge for assembly of the models which have constraint to the alignment. Model library of each component of the bridge can be prepared using existing experience.

\subsection{Pilot applications}

Initial version of the twin models except interoperability of FE analysis was developed for a cable-stayed bridge in Korea. After survey of the information and requirements for two years, a pilot maintenance system was developed and has been testing until now. The most time-consuming task in the maintenance is field inspection and its documentation. A site inspection program was also developed for damage recording with mobile devices. Synchronized process both in the site and the office allow concurrent engineering of the maintenance. AR device was tested for visualization and recording. However, there are several limitations for the tasks especially inside of the stiffening girder.

Second version of the twin model is now developing for a suspension bridge. Two challenging techniques are included in the system. One is inspection by point cloud data for more realistic models as well as automatic damage recognition. The other is the interoperability of analysis for the link with monitoring system. Sensor data can be used for the updating of the bridge models.

Figure 5 Digital twin model of a stiffening girder

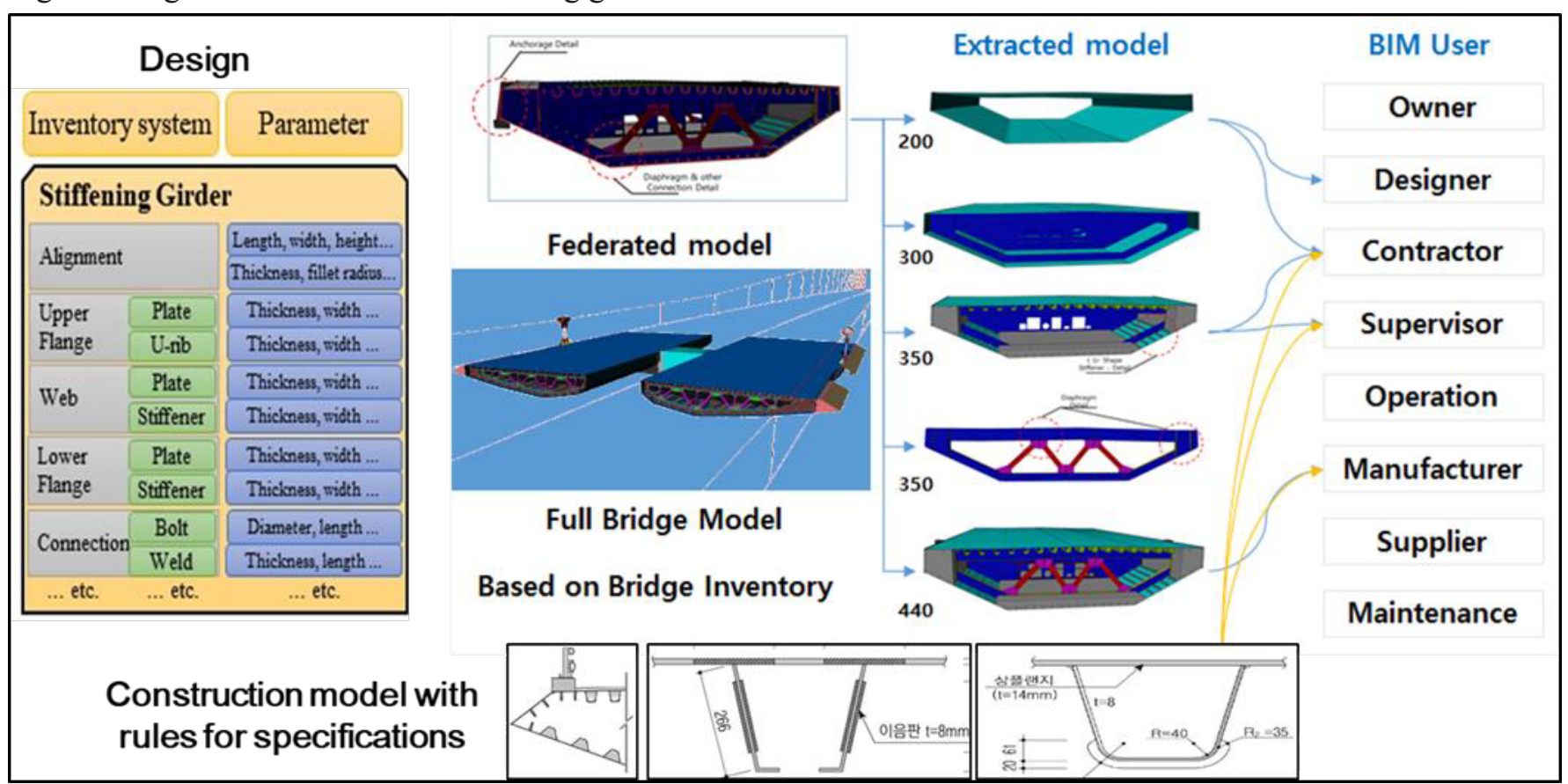

Current practice of the bridge engineering has different participants for design, fabrication, construction and maintenance. Digital twin models need collaborative knowledge from all the participants. This is the most difficult challenge in the process of the model definition. Fortunately, fabricators start to use $3 \mathrm{D} \mathrm{CAD}$ for machines and quality control of dimensions. Contractors can use the updated 3D models for construction management considering as-fabricated dimensions.
Figure 6 shows the digital twin model for a suspension bridge in Korea. The image-based inspection techniques are now testing for a common prestressed concrete girder bridge. Labelled images for different damages need to be collected from previous inspection data. Regulations on data security for important transportation facilities are obstacle to overcome. 2D drawings for inspected damages are required official deliverables. Point cloud data or images are going to replace the current practices due to increased demand of inspection for existing structures which are aging. 
For cable-supported bridges in Korea, the initial health monitoring systems have to be upgraded, some sensors should be replaced (Chang et al., 2008). Local damages such as fatigue, corrosion and connection failure are main concerns for bridge owners. Advanced monitoring systems need analysis models for real-time assessment of bridge behaviour. A digital twin model is considered as a platform to include these new requirements for better maintenance of the bridge. Local behaviour is analysed by finite element models which are connected to the twin model parts. In the initial version of DTM, the FE analysis model is derived directly due to it is an alignment-based parametric model. The current deterioration and damage of bridge change the input structural parameters of the FE analysis model, in this scene, it is the reduction of the material model. From the second version of DTM this time, sensor data from the monitoring system is embedded and considered as a field-verified structural behaviour of the FE analysis model. The input structural parameters are totally upgraded, not only the reduction of the material model but also the natural frequency, acceleration responses, cable tension force or even the global mode shapes. From this interaction between sensor data and the analysis, it is possible to record local stress history for fatigue assessment and to update the analysis model.

Figure 6 Digital twin models for a suspension bridge

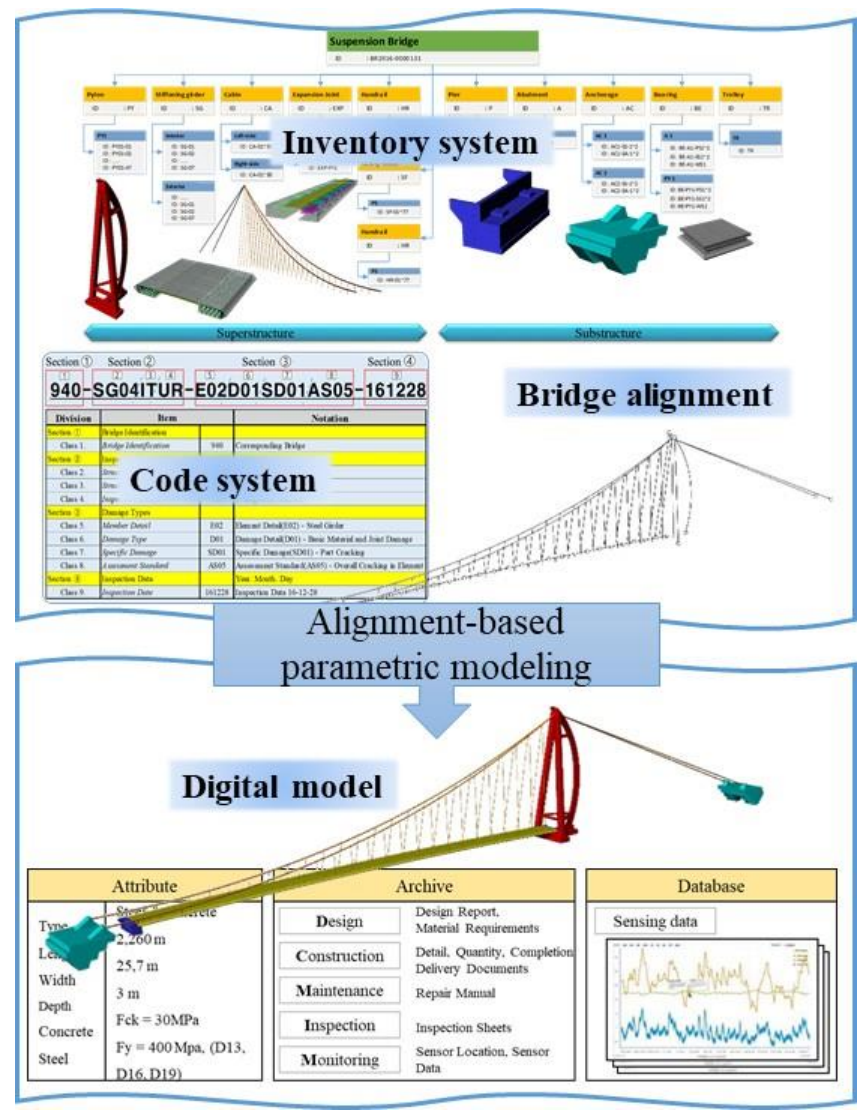

\section{Interface with a current monitoring system}

Up to now, a BIM-based maintenance system lacks of the interface with existing monitoring system. Only visualization of the monitored data is available in the maintenance system (Shim et al., 2010, 2017). Commonly initial model updating is done by dynamic responses before project delivery. When the full interaction between the model and finite element analysis is accomplished, realistic simulation of the virtual twin model can be operated by sensor data (Aron and Lane, 2017).

The finite element analysis model for a cable-supported bridge consists of frame elements and constraints. Each 3D digital model has property definitions for the analysis parameters. From the digital models, the parameter data set can be generated automatically except some objects such as main cables of suspension bridges. Constraints between objects need to be defined for the analysis (Petersen and Oiseth, 2017). Iterative calculation of the stiffness requires two-way interface of information delivery between two programs.

One more challenging issue in the analysis interoperability is to simulate deterioration model by update of digital model parameters. Effects of local damages on the global or member behaviour are not well established yet. Monitoring data are the source of the model update when new damages are observed in a bridge. Field performance data are improving empirical deterioration models of material or structural members which are based on laboratory tests.

\section{Conclusion}

In this paper, a new concept of digital twin models for the maintenance system for cable-supported bridges. Digital models represent realistic behaviour of the bridges as well as future performance. Essential consideration for the definition of the digital twin models of cable-supported bridges was proposed. Model authoring by well-organized inventories and their required information is described. DTM can has a role of a data platform during whole life cycle of a bridge.

Based on the suggested concept and surveyed information requirements, a pilot system was developed and tested. Maintenance tasks were significantly enhanced due to the federated models. More possibility to use recent technologies was found by the initial application. Smart maintenance needs well defined digital twin models as well as curated knowledge on bridge engineering.

\section{Acknowledgements}

This research was supported by a grant "Development of lifecycle engineering technique and construction method for global competitiveness upgrade of cable bridges (16SCIPB119960-01)" from Smart Civil Infrastructure Research Program funded by MOLIT and KAIA. 


\section{References}

Aron P and Lane W (2017) Industry 4.0 and the Digital Twin, Deloitte Anjin Review No. 9, pp. 64-72.

Atorod A et al. (2013) Design Guide for Bridges for Service Life, Strategic Highway Research Program, Transportation Research Board, SHRP 2 Renewal Project R19A.

Chang SP et al. (2008) Health monitoring system of a selfanchored suspension bridge (planning, design and installation/operation), Structure and Infrastructure Engineering, 4(3):193-205, 10.1080/15732470500254790.

Dang NS et al. (2018) 3D digital twin models for bridge maintenance, Proceedings of $10^{\text {th }}$ International Conference on Short and Medium Span Bridges, Quebec city, Quebec, Canada.

Dang NS and Shim CS (2018) BIM authoring for an imagebased bridge maintenance system of existing cable-supported bridges, IOP Conference Series: Earth and Environmental Science, 143(1): 012032.

Korean Group of IABSE (2012) Korean Bridge Technology, 18th IABSE Congress, Seoul, Korea.

Lee KM et al. (2010) Bridge information models for construction of a concrete box-girder bridge, Structure and Infrastructure $\quad$ Engineering. $8(7)$ : 687-703, $10.1080 / 15732471003727977$.

Mahmoud KM (2011) BTC Method for Evaluation of Remaining Strength and Service Life of Bridge Cables, New York State Bridge Authority, New York, NY, USA, NYSDOT Report C-07-11.

Maybaurl RM and Camo S (2004) Guidelines for Inspection and Strength Evaluation of Suspension Bridge Parallel Wire Cables, Transportation Research Board, Washington DC, USA, Report NCHRP 534.

Petersen $\varnothing \mathrm{W}$ and Oiseth $\varnothing$ (2017) Finite element model updating of a long span suspension bridge, Proceedings of International Conference on Earthquake engineering and Structural dynamics, Reykjavik, Iceland.

Shim CS et al. (2011) Development of BIM for a Maintenance System of Subway Infrastructure, Journal of KIBIM, 1(1): 612. (in Korean)

Shim CS et al. (2011) Application of 3D Bridge Information Modeling to Design and Construction of Bridges", Procedia Engineering 14: 95-99. 10.1016/j.proeng.2011.07.010.

Shim CS et al. (2012) Three-Dimensional Information Modelbased Bridge Engineering in Korea, Structural Engineering International, 22(1): 8-13, $10.2749 / 101686612 X 13216060212834$.

Shim CS et al. (2016) 3D Information Model Based Bridge maintenance, Proceedings of the 5th International Technical Conference, Kota Kinabalu, Malaysia, Nov., pp. 449-455

Shim CS et al. (2017) Development of BIM-based bridge maintenance system for cable-stayed bridges, Smart Structures System, 20(6): 697-708, 10.12989/sss.2017.20.6.697.
Shim CS et al. (2019) Development of a bridge maintenance system for PSC bridges using 3D digital twin model, Structure and Infrastructure Engineering. Under review 